Conclusion Hormonal evidence of gonadal failure is more common post-HSCT in females than males. Growth and thyroid adverse effects are rare. Children with haemoglobinopathy seem to have a decreased burden of endocrine late-effects post-HSCT compared with oncology patients.

\section{G96 A NATIONAL SURVEY OF EVALUATION AND TREATMENT OF HYPERTENSION IN PAEDIATRIC PATIENTS WITH DIABETES}

doi:10.1136/archdischild-2013-304107.108

M Gupta, P Raffeeq. University Hospital of North Staffordshire, Stoke on Trent, UK

Aims We conducted a postal survey of paediatric diabetic units in NHS Hospitals across the United Kingdom regarding their practise of evaluation and management of hypertension in paediatric patients with both Type 1 and Type 2 diabetes.

Methods A questionnaire was sent to different units across the UK. Addresses of units were identified from the directory of diabetic care 2008. Questionnaires were sent to 151 units in month of June 2012. Response was awaited for 12 weeks. 69 responses were received. The data were analysed using Microsoft excel

Results Out of 151 units 69 units replied, giving a response rate of $45 \%$. Of the units that replied, $10 \%$ of the units have written guidelines. $88 \%$ of the units have some form of age and height based chart to identify hypertension. $50 \%$ of the units check blood pressure annually during diabetic annual review whilst other more frequently. Only $45 \%$ of the units consider microalbuminuria as a trigger to initiate investigation. $73 \%$ of the units undertake 24 hours ambulatory blood pressure monitoring prior to starting antihypertensive therapy. For further confirmation and management of hypertension $62 \%$ of the units refer these children for joint management with nephrologist. Our survey revealed a wide variation and inconsistencies in practise of evaluation and management of hypertension in this high risk patient group. There is also a variation in the choice of antihypertensive medication amongst different units.

Conclusion There is a need for national consensus on evaluation and management of hypertension in children with diabetes which will help in standardisation of the care and consequently reduce the morbidity related to its long term complications.

\section{G97 RANGE OF URINARY STEROID METABOLITE RATIOS IN CHILDREN UNDERGOING INVESTIGATION FOR SUSPECTED DISORDERS OF STEROID SYNTHESIS}

doi:10.1136/archdischild-2013-304107.109

${ }^{1} \mathrm{~A}$ Lucas-Herald, 'M Rodie, ${ }^{1} \mathrm{~N}$ Liu, ${ }^{2} \mathrm{~K}$ Rankin, ${ }^{2} \mathrm{~N}$ Watson, ${ }^{1} \mathrm{M}$ Donaldson, ${ }^{1} \mathrm{MG}$ Shaikh, ${ }^{3} \mathrm{~J}$ McNeilly, ${ }^{2} \mathrm{D}$ Shapiro, 'SF Ahmed. 'Department of Child Health, RHSC Yorkhill, Glasgow, UK; 'Department of Biochemistry, GRI, Glasgow, UK; ${ }^{3}$ Department of Biochemistry, Southern General Hospital, Glasgow, UK

Background Calculation of a urinary steroid metabolite ratio (uSMR) may be a useful method of improving diagnostic yield when investigating disorders of steroid hormone synthesis.

Objective and hypothesis: To investigate the range of USMR in children with suspected disorders of steroid hormone synthesis.

Population/Methods Ten ratios were calculated on steroid metabolite data analysed by GC-MS in urine samples collected between 2008-2010 from 219 children who were undergoing investigations. To obtain reference data, urine samples were also analysed in 89 children with no background of endocrine concerns and who had a urine sample collected at presentation to the hospital with an acute illness.

Results Of the 89 reference children, 36(40\%) were male and median age at time of the test was 3 yrs(range,1month-11yrs). Of the 219 endocrine patients, 64(29\%) were boys. In 129(59\%) cases, a urine sample was collected to investigate early or exaggerated signs of adrenarche. Median age at test was 7.4yrs(1day-18yrs). Median and ranges of 2 steroid ratios used in the diagnosis of 21-hydroxylase deficiency are demonstrated in the Table.

Abbreviations: 17HP: 17-hydroxypregnanolone, PT: pregnanetriolone, THE: tetrahydrocortisone, THF: tetrahydrocortisol.

\section{Abstract G97 Table 1}

\begin{tabular}{llll}
\hline & $<$ 6months & 6months $-<$ 10yrs & 10yrs-18yrs \\
\hline 17HP/ & & & \\
(THE+THF+5alphaTHF) & & & \\
Reference boys & $0.014(0.005-0.08)$ & $0.005(0.00-0.25)$ & $0.025(0.003-0.08)$ \\
Affected boys & $0.014(0.005-0.102)$ & $0.008(0.001-0.37)$ & $0.017(0.001-0.183)$ \\
Reference girls & $0.11(0.025-0.005)$ & $0.006(0.00-0.033)$ & $0.011(0.003-0.069)$ \\
Affected girls & $0.026(0.006-0.089)$ & $0.008(0.001-0.08)$ & $0.02(0.003-0.089)$ \\
PT/(THE+THF+5alphaTHF) & & & \\
Reference boys & $0.024(0.008-0.031)$ & $0.021(0.00-0.283)$ & $0.108(0.025-0.482)$ \\
Affected boys & $0.046(0.003-0.186)$ & $0.027(0.003-0.103)$ & $0.049(0.019-0.693)$ \\
Reference girls & $0.012(0.009-0.035)$ & $0.019(0.006-0.128)$ & $0.065(0.029-0.223)$ \\
Affected girls & $0.039(0.013-0.187)$ & $0.039(0.005-0.351)$ & $0.085(0.044-0.299)$ \\
\hline & & &
\end{tabular}

Conclusions These novel data show that reference ranges for urinary steroid metabolite data need to be age matched. Most children with suspected disorders of steroid synthesis have a ratio which is within the reference range and the identification of outliers will lead to better targeting of genetic analyses.

\section{G98 MULTIDISCIPLINARY ASSESSMENT FOR BARIATRIC SURGERY IN ADOLESCENTS: A PILOT PROJECT FROM A NATIONAL REFERRAL SERVICE}

doi:10.1136/archdischild-2013-304107.110

${ }^{1} \mathrm{ME}$ Ford-Adams, ${ }^{1} \mathrm{H}$ Mortimer, ${ }^{2} \mathrm{D}$ Bevan, ${ }^{2} \mathrm{SS}$ Datta, ${ }^{2} \mathrm{MT}$ Lax-Pericall, ${ }^{1} \mathrm{~A}$ Desai. ${ }^{1}$ Department of Paediatrics, Kings College Hospital NHS Foundation Trust, London, UK; ' ${ }^{2}$ Dept of Child \& Adolescent Psychiatry, Institute of Psychiatry at the Maudsley, London, UK

Introduction Obesity has medical, social, psychological, familial and dietary underpinnings. We report the results of multidisciplinary assessments in adolescent bariatric surgery patients in the UK.

Aim 1. Multidisciplinary assessment of patients prior to bariatric surgery. 2. Compare outcomes from bariatric surgery to conventional treatment in the obesity clinic.

Methods 2F, 2M, mean age 14 yrs (12-18yrs) were selected for bariatric surgery. One boy with Oestegenesis Imperfecta (OI) had decrease mobility secondary to excess weight. Mean BMI $45 \mathrm{~kg} / \mathrm{m}^{2}$ $\left(38-52 \mathrm{~kg} / \mathrm{m}^{2}\right)$. They were jointly assessed by a paediatrician and paediatric surgeon. Investigations completed: Full blood count, electrolytes, Vitamin D, liver ultrasound, fasting insulin and glucose. Secondary assessment by dietetics and child psychiatry looked at as binge patterns, night eating, comorbid psychopathology and family functioning. Quality of life score (Impact on weight on QualityKids IWOOL) and Becks Anxiety inventory (BAI) were performed. Operations were performed by a paediatric surgeon and experienced adult bariatric surgeon. Three had lap bands fitted, the boy with OI underwent a sleeve gastrectomy. Pre and post surgery data were collected.

Results All surgical patients lost weight over 3 months. Mean loss $-10 \mathrm{~kg} / \mathrm{m}^{2}\left(5-17 \mathrm{~kg} / \mathrm{m}^{2}\right)$. The non surgical group had a mean gain $+1.9 \mathrm{~kg} / \mathrm{m}^{2}\left(-4-10 \mathrm{~kg} / \mathrm{m}^{2}\right)$. Improvement in clinical parameters was also seen: insulin resistance (HOMA-IR) fell from 4.5 to 1.7, mean systolic blood pressure ( $\mathrm{mmHg}$ ) dropped 139 to 126 , mean waist circumference (cm) from 121 to $116 \mathrm{~cm}$, hepatic steatosis disappeared in 3 patients who demonstrated it and Vitamin D $(\mu \mathrm{g} / \mathrm{l})$ levels rose from 10 to 35.4. There were no significant complications. Constipation and nausea reported in 2 of the 4 . All patients reported improvement in their well being. IWQOL improved mean scores in 